\section{WEB WATCH}

Riken mutants go online

- http://www.gsc.riken.go. jp/Mouse/

Riken has just released a new web resource that provides detailed information on mutant mice generated by its Mouse Functional Genomics Research Group in a largescale ENU-mutagenesis screen.

This new web site is easily navigable and contains information on the screen along with search tools to identify mutants by their phenotype. Mice are classified according to their phenotypes and were tested in several phenotypic screens that ranged from the general such as screens for gross dysmorphology or behavioural phenotypes to the more specific - for example, for haematological, urinary or hearing defects.

Mice can be searched for, through a single query form, according to the phenotypic screen they scored positively in, and searches can be further refined with keywords. The search result provides a general description of a mutant's phenotype, including information on the founder and the mutation's mode of inheritance. Videos or photographs of each mutant are also provided, and moredetailed phenotypic information is available through links to a mouse's score for each screen it was tested in.

The phenotypic information available for each mouse is considerable and is presented in a clear way, such that the detail is there if you want it. There was, however, one page that was less informative, regarding the one piece of information that most site visitors will want. How do I get hold of these mice? It's not stated on the site but apparently the mice will be available through material transfer agreements with the Riken BioResource Centre. No doubt, the email addresses provided here for more information will be well used in the following months.

Jane Alfred

GENE MAPPING

\title{
Fast fly maps at a SNP
}

Traditional approaches to mapping and positionally cloning mutations in Drosophila are somewhat limited and laborious, requiring many crosses to deficiency or marker stocks. To overcome these shortcomings, Jurg Berger and colleagues have identified a new panel of polymorphic markers, which they have used to map quickly and precisely three novel mutations in a cross between two commonly used fly strains. Many of the markers they identified are polymorphic in several other popular fly strains as well, providing a potentially widely applicable and valuable mapping resource to fly geneticists.

Berger et al. generated a panel of informative polymorphic markers by PCR amplifying and sequencing $\sim 1-\mathrm{kb}$ fragments of non-repetitive and non-coding DNA at regular intervals across each autosomal arm of two fly strains. Of the 821 pairs of PCR products screened, 787 contained at least one sequence polymorphism, and they identified 7,223 SNPs and 1,392 insertions/deletions in total. These polymorphisms can be used to map mutations on chromosomes that have recombined during meiosis - SNPs that segregate with a mutation on such chromosomes indicate where a mutation lies (see picture).

The authors picked two well-known fly strains for this study - one that carries an FRT site, which is recognized by FLP, a site-specific recombinase, and one that carries the dominant white $^{+}$marker gene, which encodes the red eye pigment. To identify flies with informative recombinant chromosomes, they generated mitotic clones - a well-known genetic approach to creating mosaic tissue. This strategy allows chromosomes on which the white $^{+}$marker and a mutation on the FRT strain have recombined to be identified because they give rise to white patches of eye tissue following FLP-induced mitotic recombination in the eye (see picture). The presence of these patches indicates that meiotic recombination has occurred between the FRT site and the white $^{+}$marker, which flank the mutation. This approach allowed the authors to save both time and resources by genotyping only those flies that carried informative recombinant chromosomes. Furthermore, because many of the markers they identified are polymorphic between other pairs of fly strains, other strains that carry visible markers could be used in a similar approach to look for recombinants in a specific interval.

Berger et al. tested their strategy by mapping three mutations - generated by chemical mutagenesis in three FRT-carrying strains — in flies with abnormal neuronal connectivity phenotypes. Mutant flies with recombinant chromosomes were identified by their mosaic eye colour and were genotyped with a panel of polymorphic markers. Two mutations were mapped to $169-\mathrm{kb}$ and $307-\mathrm{kb}$ intervals, identifying in one case a new allele of misshapen. To test whether they could reach a higher map resolution, the authors created a dense SNP map in the region of the third mutation and mapped it to a $2-\mathrm{kb}$ interval, locating the mutation to the dead-ringer gene.

The rapid and efficient application of these markers, and their usefulness in other fly strains, bodes well for their widespread use by the fly community, and could mean that positional-cloning bottlenecks become but a distant memory for fly gene hunters.

Jane Alfred

(0) References and links

ORIGINAL RESEARCH PAPER Berger, J. et al. Genetic mapping with SNP markers in Drosophila. Nature Genet. 10.1038/ng773 (2001) WEB SITES

Barry Dickson's lab: http://www.at.embnet.org/molb/PhD/Research/ IMP/Dickson/dickson.htm

Animation of mitotic clone generation: http://www.nature.com/nrg/ journal/v2/n8/animation/nrg0801_620a_swf_MEDIA1.html
Image of eye courtesy of Barry Dickson and Gabriele Gahmon, Institute of Molecular Pathology, Vienna, Austria.

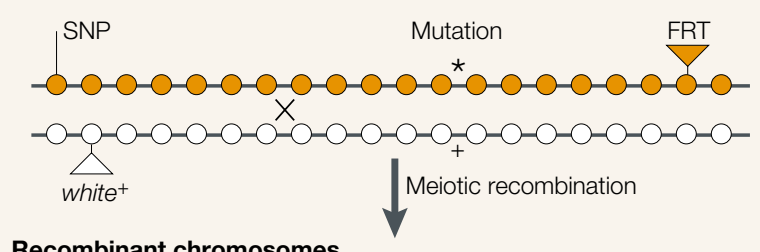

Recombinant chromosomes

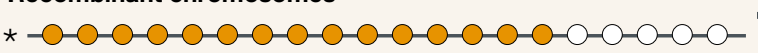

* $-\mathrm{O}-\mathrm{O}-\mathrm{O}-\mathrm{O}-\mathrm{O}-\mathrm{O}-\mathrm{O}-\mathrm{O}-\mathrm{O}-\mathrm{O}-\mathrm{O}-\mathrm{O}-\mathrm{O}-\mathrm{O}-\mathrm{O}-\mathrm{O}-\mathrm{O}-\mathrm{O}-\mathrm{O}-\mathrm{O}-$

$+-\mathrm{O}-\mathrm{O}-\mathrm{O}-\mathrm{O}-\mathrm{O}-\mathrm{O}-\mathrm{O}-\mathrm{O}-\mathrm{O}-\mathrm{O}-\mathrm{O}-\mathrm{O}-\mathrm{O}-\mathrm{O}-\mathrm{O}-\mathrm{O}-\mathrm{O}-\mathrm{O}-\mathrm{O}-\mathrm{O}-$

$+-\mathrm{O}-\mathrm{O}-\mathrm{O}-\mathrm{O}-\mathrm{O}-\mathrm{O}-\mathrm{O}-\mathrm{O}-\mathrm{O}-\mathrm{O}-\mathrm{O}-\mathrm{O}-\mathrm{O}-\mathrm{O}-\mathrm{O}-\mathrm{O}-\mathrm{O}-\mathrm{O}-\mathrm{O}-\mathrm{O}-$

$\stackrel{+}{+}$ Phenotype

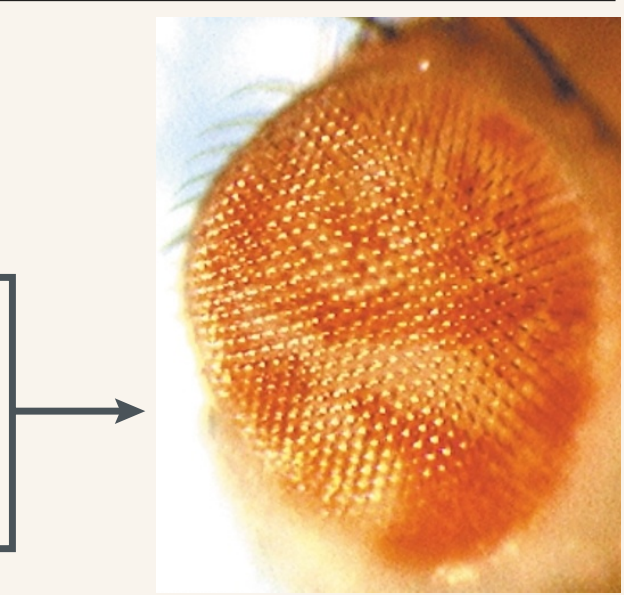

